\section{Human tumour lines}

Human Tumour Cells in Vitro. Edited by Jørgen Fogh. Pp. xix +557 . (Plenum: New York and London, 1975.) $\$ 44.50$.

THIs book, a collection of 16 papers on human tumour cell culture, has appeared at an appropriate time. Belatedly research laboratories are beginning to show an increasing interest in cancer in man and at the same time there is an increasing, if somewhat misguided, pressure from society to limit suffering in laboratory animals, particularly since it cannot or will not limit suffering among men. Consequently in vitro systems, especially those using human tissue, are becoming increasingly popular. As in any branch of science the value of a particular technique depends on the questions it is being using to answer. If cell cultures are being used for virus production or cytotoxicity testing (for example), the nature of the cells is unimportant provided they serve the purpose of the experiment. If the experiments are concerned with the nature and behaviour of the cells themselves a more critical approach is required.

It is important to know the precise origin of the cells and the variations in structure and function which they may have developed as a consequence of establishment in vitro. This was well known to the early practitioners of the art of cell culture-all of whom were biologists or physicians accustomed to studying the whole individual _-but with the expansion of cell and molecular biology, concerned principally with isolated cells, and an era when living cells could be ordered and supplied 'off the shelf' by laboratory supply houses, these basic facts were often forgotten. Although the whole universe may be contained in a grain of sand the whole of biology is not contained in a Hela or BHK cell. Why for example is it possible to maintain such a small proportion of tumour cells in culture as permanently established cell lines? How can tumour cells in vitro be identified with certainty and distinguished from mesenchymal cells arising from the non-malignant stroma of the tumour? Human Tumour Cells in Vitro considers some of these problems.

Apart from a valuable description of 31 new human tumour lines by the editor and Dr Trempe, most of the information is available elsewhere to those with access to a good library but for the others it provides a useful survey of methods and media which have been used for the establishment of human tumour cell lines in vitro. There are also sections on cytological characterisation, chromosome abnormalities and ultrastructure and on the search for viruses in human cancer cells.

L. M. Franks

\section{Pineal physiology}

Frontiers of Pineal Physiology. Edited by Mark D. Altschule. Pp. xii +269 .

(MIT : Cambridge, Massachussetts and London, 1975.) £8.75.

IT would be a pity if this book were read as an entreé to the new and exciting realm of pineal physiology; its title stakes a claim which is wholly unjustified by its contents, a collection of papers (some reviews, others research reports, yet others an uneasy mixture of the two) uneven both in length and quality. Five years have passed since the conference on which it is based was held, and this latent period is all too obvious in places.

The intense enzymatic activity of the pineal, and the way this is changed by either natural or experimental lighting are characteristic features. Three chapters survey this area, with varying degrees of thoroughness. A firmer editorial hand might have improved the organisation of this part of the book, and reduced the considerable overlap between individual chapters; much of these have also appeared in other reviews by the same authors.

Although studies on pineal function are still dominated by the discovery of melatonin, increasing attention is now being given to pineal polypeptides, some of which seem to resemble those found in the hypothalamus and pituitary; two research reports deal with these substances. P. H. Sampson contributes a brief survey on the way the pineal may be involved in various categories of behaviour, most of which is a lengthy report of an experiment showing that pinealectomy somewhat reduced maternal behaviour. We are left wondering what this might mean in terms of pineal function, for no interpretation is offered.

The most intriguing, and inevitably the most controversial, part of the book explores the possible association between malfunction of the pineal and schizophrenia. The large amount of 5-hydroxytryptamine in the pineal and the suspicion that this monoamine is involved in schizophrenia make the link tempting (although drugs ameliorating this condition are generally dopamine blockers). M. D. Altschule contributes a chapter which is too brief either to inform adequately or to convince in which it is said that administering pineal extracts improves abnormalities in carbohydrate metabolism in schizophrenics, although how these are related to the disease is unclear. L. B. Bigelow describes the results of a trial in which schizo- phrenics were given daily injections of melatonin-free pineal extract. In spite of a curious method of measuring the patient's mental state, an uneven baseline and coincident changes in phenothiazines, the results of at least one case suggest the need for a more comprehensive study. Dr Bigelow quotes the isolation from the pineal of a substance inhibiting the formation of dimethyltryptamines, long known to be hallucinogenic. What a pity his study didn't concentrate specifically on these symptoms.

This book represents the frontiers of our knowledge indistinctly, and the signposts to the future are hard to discern from reading it. J. Herbert

\section{Xylem strategy}

Ecological Strategies of Xylem Evolution. By Sherwin Carlquist. Pp. xi+ 259. (University of California : Berkeley, Los Angeles and London, August 1975.) £6.85.

ThIS book is profoundly disappointing. The subject matter does have general interest. Do such features as the lengths of tracheids and vessel elements, the shapes and sizes of these cells in transverse section and the shapes and sizes of the pits between these cells have any significance in the adaptation of plants to their habitats? Is the disposition of parenchyma and fibres within and around the xylem of adaptive significance? Any satisfying book would have to start from a statement of theory regarding the functional effects of these features, together with such experimental evidence as is available. The author offers no such opening statement, although relevant comments are scattered through the book. He considers each major vascular group in turn, seeking an exact harmony between certain arbitrarily chosen xylem features and the habitat of the plant. The whole account is riddled with unsupported statements, special pleading and illogical handling of facts and ideas. The author never deals adequately with the phenotypic as opposed to genotypic differences between plants; slower-growing individuals generally have shorter, narrower xylem elements, but is this feature necessarily adaptive? There are some suggestive correlations of habitat with xylem cell form, but in respect of most of the detailed differences in xylem type one is bound to agree that "the logical conclusion to be drawn is that a variety of peculiar types are functionally quite effective" ( $\mathrm{p} 23$ ). This book should have been condensed into a review article.

P. J. Grubb 